\title{
Addition of salmeterol versus doubling the dose of fluticasone propionate in patients with mild to moderate asthma
}

\author{
J A van Noord, A J M Schreurs, S J M Mol, P G H Mulder
}

\begin{abstract}
Background-The objective of this multicentre, randomised, double blind, parallel group study was to compare the efficacy and safety of the addition of salmeterol with that of doubling the dose of fluticasone propionate in asthmatic patients not controlled by a low or intermediate dose of inhaled corticosteroids.
\end{abstract}

Methods-After a four week run in period of treatment with fluticasone propionate (100 $\mu \mathrm{g}$ twice daily if pre-trial dose was 400-600 $\mu \mathrm{g}$ inhaled corticosteroids or $250 \mu \mathrm{g}$ twice daily if pre-trial dose was 800-1200 $\mu$ g inhaled corticosteroids), 274 patients were randomised to treatment for 12 weeks with either salmeterol $50 \mu \mathrm{g}$ twice daily plus the run in dose of fluticasone propionate or twice the run in dose of fluticasone propionate $(200$ or $500 \mu \mathrm{g}$ twice daily). Outcome measures were daily records of peak expiratory flow (PEF), symptom scores, and clinic lung function.

Results-The improvements in both the morning and evening PEF were better in the salmeterol than in the fluticasone propionate group, the mean increase in morning PEF being 19 1/min higher (95\% CI 11.0 to 26.1) and in evening PEF being $161 / \mathrm{min}$ (95\% CI 18.4 to 24.0 ) higher in the salmeterol group. The increase in forced expiratory volume in one second $\left(\mathrm{FEV}_{1}\right)$ was 0.091 greater in the salmeterol group than in the fluticasone propionate group after four weeks of treatment $(95 \%$ CI 0.01 to 0.18 ), but not after 12 weeks. Both regimens showed an increase in symptom free days and a reduction in the need for rescue salbutamol both during the day and the night, but these improvements were greater in the salmeterol group. There were no significant differences between the groups in adverse effects or in the number of rescue courses of oral corticosteroids.

Conclusions-In this group of patients still symptomatic despite 100 or $250 \mu \mathrm{g}$ fluticasone propionate twice daily, the addition of salmeterol caused a greater improvement in lung function and symptom control than doubling the dose of fluticasone propionate.

(Thorax 1999;54:207-212)

Keywords: salmeterol; fluticasone propionate; asthma
In international guidelines inhaled corticosteroids are considered the primary treatment for persistent asthma ${ }^{1}$ and inhaled short acting $\beta_{2}$ agonists are recommended for relief of symptoms as needed. If patients remain symptomatic two of the available options are to increase the dose of inhaled corticosteroids or to add a long acting $\beta_{2}$ agonist.

Inhaled corticosteroids have been shown to improve lung function and symptoms, to decrease airway hyperresponsiveness, and to reduce the number of asthma exacerbations. ${ }^{1-4}$ Long acting inhaled $\beta_{2}$ agonists have been shown to improve lung function and symptom score, to decrease nocturnal asthma, and to decrease the need for short acting $\beta_{2}$ agonists. ${ }^{56}$ On the other hand, the regular use of short acting $\beta_{2}$ agonists has been associated with less good asthma control and an increase in the number of exacerbations. ${ }^{7}$ Accordingly, there are concerns that maintenance therapy with long acting $\beta_{2}$ agonists could lead to deterioration of asthma control. Recently, however, three large trials by Greening et $a l,{ }^{8}$ Woolcock et $a l,{ }^{9}$ and Pauwels et $a l^{10}$ have reported that the combination of the long acting $\beta_{2}$ agonists salmeterol or formoterol with the inhaled corticosteroids beclomethasone dipropionate (BDP) or budesonide (BUD) provide better improvement in lung function and symptom control, without increasing the exacerbation rate, than doubling the dose of the inhaled corticosteroid.

To date no studies have been performed using the combination of salmeterol (SLM) and fluticasone propionate (FP). This study was therefore undertaken to compare the effects on lung function and symptom control of adding salmeterol or doubling the dose of FP in asthmatic subjects still symptomatic on a low or intermediate dose of inhaled corticosteroids.

\section{Methods}

PATIENTS

Asthmatic patients aged at least 18 years and receiving $400-600 \mu \mathrm{g}$ BDP or $800-1200 \mu \mathrm{g}$ BUD daily were recruited to the study. Patients were excluded if they had changed their asthma medication in the preceding six weeks, had used oral steroids in the previous three months, had an upper or lower respiratory tract infection requiring antibiotic treatment, or had been admitted to hospital for their asthma in the previous month.

The study was performed at 27 centres in The Netherlands and was approved by the medical ethics committee of each study hospi-

12 October 1998

Accepted for publication

17 November 1998 
Table 1 Stratification for pre-study dose of inhaled corticosteroids

\begin{tabular}{lll}
\hline $\begin{array}{l}\text { Pre-study dose of } \\
\text { inhaled steroid }\end{array}$ & Run in period & Treatment period \\
\hline $400-600 \mu \mathrm{g}$ & FP $100 \mu \mathrm{g}$ twice daily & $\begin{array}{l}\text { FP } 100 \mu \mathrm{g} \text { twice daily (open) + FP 100 } \mu \mathrm{g} \text { twice } \\
\text { daily (blind) or SLM 50 } \mu \mathrm{g} \text { twice daily (blind) }\end{array}$ \\
$800-1200 \mu \mathrm{g}$ & FP $250 \mu \mathrm{g}$ twice daily & $\begin{array}{l}\text { FP 250 } \mu \mathrm{g} \text { twice daily (open) + FP 250 } \mu \mathrm{g} \text { twice } \\
\text { daily (blind) or SLM 50 } \mu \mathrm{g} \text { twice daily (blind) }\end{array}$
\end{tabular}

$\mathrm{FP}=$ fluticasone propionate $\mathrm{SLM}=$ salmeterol.

tal. Written informed consent was obtained from all patients.

STUDY DESIGN

The study was of a randomised, double blind, parallel group design with two treatment regimens. Patients were stratified into two groups depending on their baseline inhaled steroid dose. Those on a pre-trial dose of 400 $600 \mu \mathrm{g} /$ day received FP $100 \mu \mathrm{g}$ twice daily (low dose group) and those on a pre-trial dose of 800-1200 $\mu \mathrm{g}$ inhaled corticosteroids received FP $250 \mu \mathrm{g}$ twice daily (high dose group), all via Diskhaler (table 1). Random allocation of patients to each treatment regimen was performed for each group.

The study comprised a run in period of four weeks and a treatment period of 12 weeks. There were five scheduled visits to the clinic: at the start of the run in period (visit 1), after two weeks of the run in period (visit 2), at the start of treatment (visit 3), after four weeks of treatment (visit 4), and after 12 weeks of treatment (visit 5).

At visit 1 all short acting $\beta_{2}$ agonists were replaced with salbutamol (400 $\mu \mathrm{g}$ by Diskhaler). Methylxanthines and anticholinergics were permitted in stable doses. At the end of the run in period patients were eligible for randomisation if they fulfilled the following inclusion criteria: (1) forced expiratory volume in one second $\left(\mathrm{FEV}_{1}\right)$ at least $50 \%$ of the predicted value at visit 3 ; (2) an increase in $\mathrm{FEV}_{1}$ of at least $10 \%$ predicted $\mathrm{FEV}_{1}$ from baseline after inhalation of $400 \mu \mathrm{g}$ salbutamol from a metered dose inhaler or $800 \mu \mathrm{g}$ from a dry powder inhaler at visit 1,2 or 3 , or during the month prior to the run in period; (3) either a total daytime plus night time symptom score of $\geqslant 1$, or a diurnal variation in peak expiratory flow (PEF) of at least $15 \%$, or use of rescue salbutamol on two or more occasions per 24 hours on at least four days of the last two weeks of the run in period. The diurnal variation in PEF was calculated from the formula: ((PEF evening-PEF morning)/PEF evening) $\times 100$.

Eligible patients in the low dose group were randomly assigned to receive either FP $100 \mu \mathrm{g}$ twice daily (open) + FP $100 \mu \mathrm{g}$ twice daily (blind) or FP $100 \mu \mathrm{g}$ twice daily (open) + SLM $50 \mu \mathrm{g}$ twice daily (blind). Those in the high dose group were randomly assigned to receive either FP $250 \mu \mathrm{g}$ twice daily (open) + FP $250 \mu \mathrm{g}$ twice daily (blind) or FP $250 \mu \mathrm{g}$ twice daily (open) + SLM $50 \mu$ g twice daily (blind) (table 1). All medications were inhaled via Diskhaler.
OUTCOME PARAMETERS

Diary card data

During the run in and treatment periods all patients filled in a daily diary card, recording their morning and evening PEF, daytime and night time symptoms, and use of rescue salbutamol. PEF was measured using a miniWright peak flow meter before taking the study medication. The best of three measurements was retained. The use of rescue medication within six hours of the measurements was also recorded. Daytime symptoms were recorded using a scale of 0 (no symptoms) to 5 (severe symptoms precluding normal activities). Night time symptoms were scored using a scale of 0 (no symptoms) to 4 (did not sleep at all).

\section{Clinic visits}

At each scheduled visit details of adverse events, deterioration of asthma symptoms, and withdrawals were recorded, diaries were reviewed and forced vital capacity (FVC), $\mathrm{FEV}_{1}$ and PEF (using the patient's own peak flow meter) were measured. All lung function measurements were performed during the morning, 12-16 hours after the last dose of the study medication and at least eight hours after the last dose of rescue salbutamol. The best of three technically adequate measurements was retained.

In case of a deterioration of asthma symptoms despite the use of more than six times rescue salbutamol daily, the patients were asked to return to the outpatient clinic and were treated with a seven day course of oral prednisone, tapering off the daily dosage as follows: $35,30,20,10,10,5,5 \mathrm{mg}$ per day, respectively.

\section{STATISTICAL ANALYSIS}

In this study two treatment regimens were compared: either doubling the existing dose of FP or adding $50 \mu \mathrm{g}$ SLM twice daily to the existing dose of FP. According to the existing dose of FP there were two groups of patients (100 $\mu \mathrm{g}$ twice daily and $250 \mu \mathrm{g}$ twice daily). The statistical analyses were performed on both groups combined. As the distribution of patients over both groups reflects that in the general population of patients with mild or moderate asthma, the results of the combined

Table 2 Characteristics of the randomised patients at start of the run in period

\begin{tabular}{lcc}
\hline & $\begin{array}{l}\text { Fluticasone } \\
\text { propionate }+ \\
\text { salmeterol }(n=139)\end{array}$ & $\begin{array}{l}\text { Fluticasone } \\
\text { propionate double } \\
\text { dose }(n=135)\end{array}$ \\
\hline Sex (F/M) & $73 / 66$ & $68 / 67$ \\
Age (years) & $46(15)$ & $47(14)$ \\
FEV $_{1}(1)$ & $2.33(0.74)$ & $2.34(0.75)$ \\
FEV $_{1}$ (\% pred) & $71(16)$ & $73(16)$ \\
FVC (1) & $3.69(1.08)$ & $3.70(1.25)$ \\
FVC (\% pred) & $94(17)$ & $96(18)$ \\
PEF (1/min) & $348(110)$ & $358(129)$ \\
PEF (\% pred) & $75(21)$ & $75(20)$ \\
Reversibility & & \\
$\quad \%$ pred FEV & \\
$\quad$ & $15(5)$ & $15(6)$ \\
\hline
\end{tabular}

Values are mean (SD).

$\mathrm{FEV}_{1}=$ forced expiratory volume in one second; $\mathrm{FVC}=$ forced vital capacity; $\mathrm{PEF}=$ peak expiratory flow; reversibility = increase in \% predicted $\mathrm{FEV}_{1}$ after $400 \mu \mathrm{g}$ salbutamol by metered dose inhaler or $800 \mu \mathrm{g}$ by dry powder inhaler; \% pred $=$ percentage of the predicted value. 

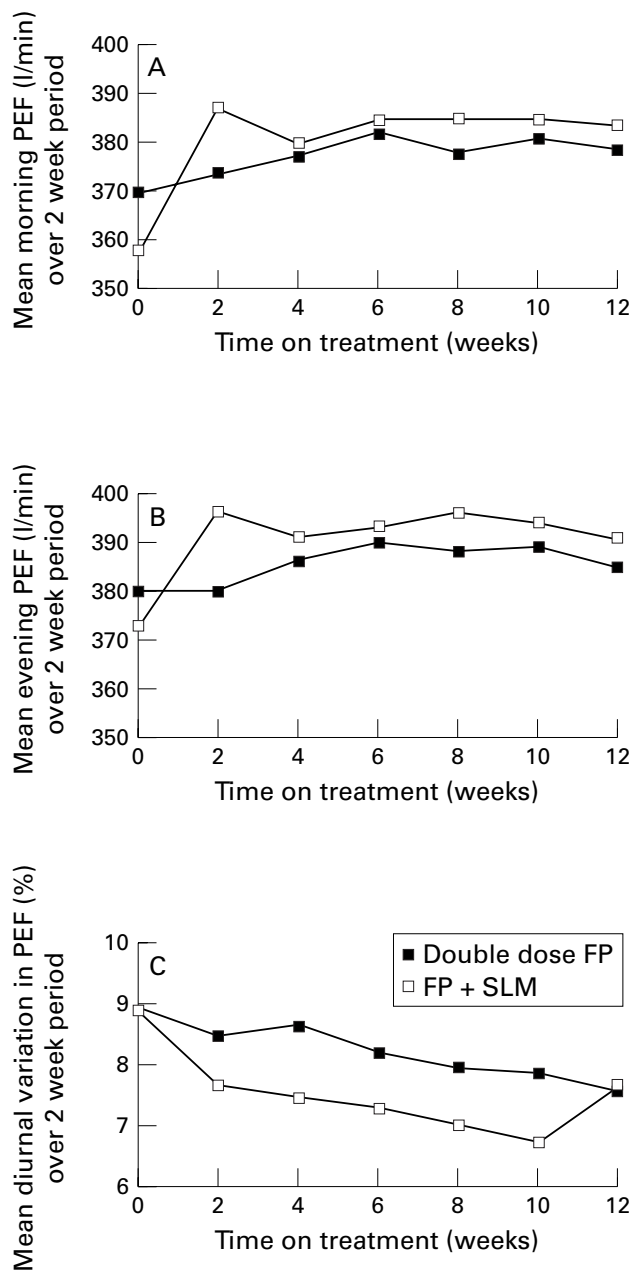

Figure 1 Mean peak expiratory flow (PEF) in $(A)$ the morning, $(B)$ the evening, and $(C)$ mean diurnal variation in PEF over two week periods before and during treatment with fluticasone propionate $(F P)+$ salmeterol (SLM) and double dose FP.

analyses are applicable to the general asthma population.

Differences between the two treatment groups in the clinic lung function parameters measured at visits 4 and 5 were analysed on each visit by means of ANCOVA with the baseline measurement at visit 3 as covariate.

The diary card data were analysed by means of repeated measures ANOVA. The total follow up period was subdivided into six periods of

Table 3 Clinic lung function during treatment

\begin{tabular}{|c|c|c|c|c|c|c|c|}
\hline & & & $\begin{array}{l}\text { Fluticasone } \\
\text { propionate }+ \\
\text { salmeterol } \\
(n=139)\end{array}$ & $\begin{array}{l}\text { Fluticasone } \\
\text { propionate } \\
\text { double dose } \\
(n=135)\end{array}$ & $\begin{array}{l}\text { Adjusted } \\
\text { difference } \\
\text { (SE) between } \\
\text { groups }\end{array}$ & $\begin{array}{l}95 \% \\
\text { confidence } \\
\text { interval }\end{array}$ & $p$ value \\
\hline \multirow{3}{*}{$\mathrm{FEV}_{1}(1)$} & Visit & 3 & $2.38(0.75)$ & $2.39(0.75)$ & & & \\
\hline & & 4 & $2.53(0.77)$ & $2.45(0.83)$ & $\begin{array}{c}0.09 \\
(0.044)\end{array}$ & 0.01 to 0.18 & 0.04 \\
\hline & & 5 & $2.47(0.76)$ & $2.48(0.89)$ & $\begin{array}{c}0.05 \\
(0.041)\end{array}$ & 0.02 to 0.14 & 0.18 \\
\hline \multirow[t]{3}{*}{ FVC (1) } & Visit & 3 & $3.72(1.06)$ & $3.71(1.14)$ & & & \\
\hline & & 4 & $3.85(1.08)$ & $3.72(1.25)$ & $\begin{array}{c}0.13 \\
(0.053)\end{array}$ & 0.03 to 0.23 & 0.02 \\
\hline & & 5 & $3.73(1.10)$ & $3.75(1.21)$ & $\begin{array}{c}0.02 \\
(0.051)\end{array}$ & -0.08 to 0.12 & 0.64 \\
\hline \multirow[t]{3}{*}{$\operatorname{PEF}(1 / \mathrm{min})$} & Visit & 3 & 367 (114) & $365(117)$ & & & \\
\hline & & 4 & $391(111)$ & $367(115)$ & $17.6(7.4)$ & 3.14 to 32.0 & 0.02 \\
\hline & & 5 & $386(122)$ & $384(120)$ & $6.6(8.2)$ & -9.45 to 22.7 & 0.42 \\
\hline
\end{tabular}

For abbreviations see table 2 .

*Adjusted for the baseline measurement at visit 2 (ANCOVA). two weeks each and a two week baseline period. The outcome variables were 14 day average PEF values per patient per period and, for symptoms and rescue medication, the number of days with symptoms (or with rescue medication) per patient per 14 day period which were then logit transformed to normalise the multivariate distribution of the error term. The logit transformation is the natural logarithm of the ratio of the number of days with symptoms relative to the number of days without symptoms. The following explanatory factors were used in the repeated measures ANOVA: a within patient factor time (with six levels), a between patient factor treatment (with two levels), and their interaction; the baseline period was taken into account by including the logit of the baseline period as a constant (in time) covariate. Given these factors and the baseline covariate, the within patient multivariate error term was assumed to have a first order autoregressive structure.

\section{Results}

Of the 369 patients recruited into the study, 95 were excluded before randomisation because of ineligibility. The remaining 274 patients were randomised into the two treatment groups and the analysis was performed on the two groups combined.

The characteristics of the patients are shown in table 2. The groups were well balanced for all demographic data. During the treatment period 15 patients were withdrawn, nine from the FP group $(7 \%)$ and six from the SLM group $(4 \%)$. The reasons for withdrawal included violation of the protocol, adverse events, and non-compliance.

\section{PEAK EXPIRATORY FLOW}

There was no significant time effect in morning and evening PEF and there was no significant interaction between time and treatment, adjusted for the baseline peak flow (fig 1). There appeared to be a constant significant treatment effect over time. The increase in both morning and evening PEF, adjusted for baseline PEF, was higher in the SLM group than in the FP group (morning, mean (SE) 18.6 (3.84) $1 / \mathrm{min}$ (95\% CI 11.0 to 26.1 ), $\mathrm{p}<0.001$; evening, 16.2 (3.96) $1 / \min (95 \%$ CI 8.41 to 23.9 ), $\mathrm{p}<0.001$ ).

Diurnal variation was analysed after log transformation and did not show a significant treatment effect. During the run in (baseline) period the diurnal variation was $9 \%$ in both treatment groups and it decreased significantly with time $(p=0.005)$ at the same rate in both groups. In this analysis adjustment was also made for the logarithm of baseline diurnal variation.

\section{LUNG FUNCTION}

During the run in period the mean (SE) $\mathrm{FEV}_{1}$ increased by $0.07(0.02) 1(\mathrm{p}<0.001), F V C$ by 0.041 (not significant), and PEF by 16 (4.17) $1 / \mathrm{min}(\mathrm{p}<0.001)$. After four weeks of treatment (visit 4) $\mathrm{FEV}_{1}, \mathrm{FVC}$, and PEF were significantly higher in the SLM group than in the FP group with $\mathrm{p}$ values of $0.04,0.02$, and 

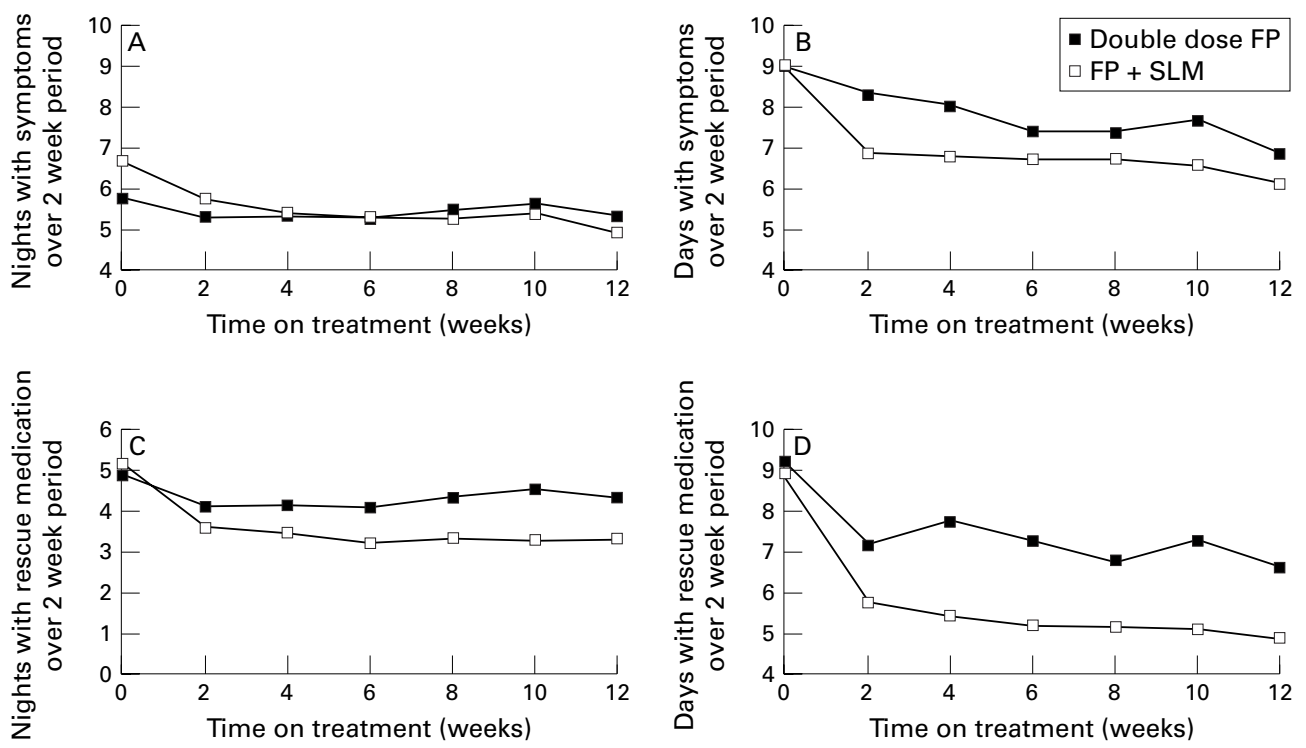

Figure 2 Mean number of $(A)$ nights with symptoms, $(B)$ days with symptoms, $(C)$ nights with rescue medication and (D) days with rescue medication per two week period before and during treatment with fluticasone propionate $(F P)+$ salmeterol (SLM) and double dose FP.

0.02 , respectively (table 3 ). After 12 weeks of treatment (visit 5) no significant differences were found between the SLM and FP groups.

SYMPTOM SCORES, RESCUE MEDICATION, AND COURSES OF ORAL STEROIDS

The evolution in time of the logit of the number of days (nights) with symptoms or rescue medication per 14 day period (the natural logarithm of the ratio of days with/without symptoms or rescue medication) was not significantly different between the two treatment groups (fig 2).

Significant treatment effects which thus were constant in time showed up in the following outcome variables, expressed as odds ratios (OR) of FP versus SLM treatment (the odds ratio is calculated as the antilog of the difference in logit between FP and SLM): (1) night time use of rescue salbutamol, OR 1.47 (95\% CI 1.04 to 2.10 ), $\mathrm{p}=0.03$; (2) daytime use of rescue salbutamol, OR 2.19 (95\% CI 1.42 to 3.40 ), $\mathrm{p}<0.001$; (3) days with symptoms, OR 1.52 (95\% CI 1.01 to 2.28$), \mathrm{p}=$ 0.04 .

Significant time effects (parallel in both treatment groups) were seen in night time symptoms $(\mathrm{p}=0.002)$, daytime symptoms $(\mathrm{p}<0.001)$, and daytime rescue medication $(\mathrm{p}<0.001)$. These time effects showed a downward trend during the treatment period (fig 2). In all these analyses adjustment was made for the baseline logit of the outcome variable concerned.

During the run in period there were five courses of oral steroids in the FP group and six in the SLM group. During the treatment period 16 patients $(12 \%)$ in the SLM group and 15 patients $(11 \%)$ in the FP group received a course of oral steroids. These differences were not statistically significant.

ADVERSE EVENTS

Both treatments were well tolerated during the 12 week study. The number of patients report- ing adverse events at the scheduled visits were not significantly different in the two treatment groups. There were four withdrawals because of an adverse event, all in the FP group.

\section{Discussion}

The results of this study show that, in patients with mild to moderate asthma still symptomatic despite maintenance therapy with $200 \mu \mathrm{g}$ or $500 \mu \mathrm{g}$ FP daily, the addition of salmeterol twice daily was superior to doubling the dose of FP in terms of better and more rapid improvement in lung function, symptom control, and need for rescue medication. Furthermore, there was no difference in rescue courses of oral steroids between the treatment groups.

Our results are in keeping with similar studies by Greening et $a l,{ }^{8}$ Woolcock et $a l,{ }^{9}$ and Pauwels et al. ${ }^{10}$ Greening et al ${ }^{8}$ reported a large group of patients with mild to moderate asthma in whom the addition of SLM $50 \mu \mathrm{g}$ twice daily was more effective at improving $\mathrm{PEF}$ and symptoms than increasing the dose of BDP from 400 to $1000 \mu \mathrm{g}$ daily. Over the treatment period of six months there was no significant difference in exacerbation rate as defined in this study between the two groups. They included no clinic lung function studies and there may be some concern about the very large number of withdrawals $(32 \%)$.

Woolcock et al studied a large group of 738 asthmatic patients who were still symptomatic while receiving $1000 \mu \mathrm{g}$ BDP daily and were randomised to treatment with either BDP $1000 \mu \mathrm{g}$ daily + SLM (50 or $100 \mu \mathrm{g}$ twice daily) or with BDP $2000 \mu \mathrm{g}$ daily for 24 weeks. The addition of SLM provided better improvement in morning and evening PEF, clinic $\mathrm{FEV}_{1}$, and symptom control than doubling the dose of BDP to $2000 \mu \mathrm{g}$ daily. Exacerbation rates did not differ between the groups and none of the treatment regimens altered bronchial hyperresponsiveness.

Pauwels et $a l^{10}$ recently reported that, over a period of 12 months of treatment, the combi- 
nation of formoterol with a low dose $(200 \mu \mathrm{g}$ daily) or a high dose ( $800 \mu \mathrm{g}$ daily) of BUD reduced the incidence of asthma exacerbations. Treatment with a higher dose of BUD, with or without formoterol, also reduced severe exacerbations. The improvement in lung function and symptom control was greater with the addition of formoterol than with a higher dose of BUD.

There are a number of differences between the above mentioned studies and our study with respect to the drugs used, the severity of asthma, definition of exacerbations, duration of treatment period, and primary outcome measures. Our study is the first to investigate the combination of SLM and FP and the results are similar to studies using BDP and BUD.

The 12 week treatment period of this study was shorter than those in the studies discussed $\left(24,26\right.$, and 52 weeks) ${ }^{8-10}$ For this reason our primary objective was to determine the effect of the different regimens on PEF measurements and symptoms. The addition of SLM resulted in a larger increase in morning and evening PEF and a greater reduction in diurnal variation of PEF. The mean improvement in clinic $\mathrm{FEV}_{1}$ in the SLM group was greater than in the FP group after four weeks but not after 12 weeks of treatment. This finding suggests that the maximum response to the increased dose of FP is much slower and takes at least four weeks. However, it is possible that one or both treatment groups might improve further after the 12 week period. The changes in subjective measures were in accordance with objective parameters. Both the increase in days and nights without use of rescue salbutamol and the increase in symptom free days was greater in the SLM group.

Several studies have shown that, during maintenance therapy with long acting $\beta_{2}$ agonists, limited tolerance develops to the bronchoprotective effects against methacholine $^{11}{ }^{12}$ or exercise ${ }^{13}$ and that this tolerance is not prevented by inhaled corticosteroids. ${ }^{14-16}$ In most studies ${ }^{511} 17$ no tolerance to the bronchodilator response of the long acting $\beta_{2}$ agonists was found, but in two placebo controlled studies with formoterol a small loss of both peak effect and duration of bronchodilatation was reported..$^{18}{ }^{19}$ In our study the addition of SLM caused a rapid increase in morning and evening PEF which remained stable throughout the treatment period. The rapid decrease in symptoms was also sustained during the treatment period. These results confirm previous reports ${ }^{10}$ that tolerance to this particular long acting $\beta_{2}$ agonist is of little clinical relevance.

The data on exacerbation rate in this study, expressed as the use of courses of oral steroids, must be interpreted with caution as the treatment period was relatively short. However, the percentage of withdrawals in the present study $(7 \%)$ was much lower than in previous studies $\left(32 \%, 12 \%\right.$, and $23 \%$, respectively)..$^{8-10}$ Although patients with relatively stable asthma were selected (no oral corticosteroids in the three months preceding the run in period and a diurnal variation in PEF during the run in period of only $9 \%$ ), there were a number of courses of oral steroids during treatment: 16 patients $(12 \%)$ in the SLM group and 15 patients $(11 \%)$ in the FP group. Thus, there was no difference in courses of oral steroids between the treatment groups. There is evidence to suggest that inhaled corticosteroids are effective in preventing asthma exacerbations. ${ }^{2}$ Verberne et $a l^{20}$ have recently reported that BDP in children is superior to SLM as a monotherapy in reducing the exacerbation rate. Finally, Pauwels et $a l^{10}$ have shown that, during treatment with the combination of formoterol and BUD, both drugs independently reduced the number of exacerbations.

We conclude from this study that, in patients with mild to moderate asthma and persistent symptoms and airflow obstruction despite low dose inhaled corticosteroids, the addition of a long acting $\beta_{2}$ agonist produced a greater improvement in lung function and symptom control than doubling the dose of inhaled steroids. Deterioration of asthma symptoms requiring a course of oral steroids did occur in both groups with similar frequency. In these patients with exacerbations the treatment of choice is probably the combination of a long acting $\beta_{2}$ agonist with a high dose of inhaled steroids.

This study was supported by Glaxo Wellcome BV, Zeist, The Netherlands.

1 NHLBI. Global initiative for asthma. Global strategy for sthma management and prevention NHLBI/WHO Worksep Report. Bethesda: NIH, NHLBI, Publication No. 95-3659, 1995.

2 Haahtela $\mathrm{T}$, Jarvinen $\mathrm{M}$, Kava $\mathrm{T}$, et al. Comparison of $\beta_{2}$-agonist, terbutaline, with an inhaled corticosteroid, budesonide, in newly detected asthma. N Engl F Med 1991; 325:388-92.

3 Van Essen-Zandvliet EE, Hughes MD, Waalkens HJ, et al. Effects of 22 months of treatment with inhaled corticosteroids and/or beta-2-agonists on lung function, airway responsiveness, and symptoms in children with asthma. Am Rev Respir Dis 1992;146:547-54.

4 Juniper EF, Kline PA, Vanzieleghem MA, et al. Effect of long-term treatment with an inhaled corticosteroid (budesonide) on airways hyperresponsiveness and clinical asthma in non-steroid-dependent asthmatics. Am Rev asthma in non-steroid-de

5 Britton MG, Earnshaw JS, Palmer JBD. A 12-month comparison of salmeterol with salbutamol in asthmatic patients. Eur Respir f 1992;5:1062-7.

patients. Eur Respir f 1992;5:1062-7.
6 Pearlman DS, Chervinsky P, LaForce J, et al. A comparison of salmeterol with albuterol in the treatment of mild-tomoderate asthma. N Engl F Med 1992;327:1420-5.

7 Sears MR, Taylor DR, Print CG, et al. Regular inhaled betaagonist treatment in bronchial asthma. Lancet 1990;336 1391-6.

8 Greening AP, Ind PW, Northfield M, et al. Added salmeterol versus higher-dose corticosteroid in asthma patients with symptoms on existing inhaled corticosteroid. Lancet 1994; 344:219-24.

9 Woolcock A, Lundback B, Ringdal N, et al. Comparison of addition of salmeterol to inhaled steroids with doubling of the dose of inhaled steroids. Am $\mathcal{f}$ Respir Crit Care Med the dose of inhaled

10 Pauwels RA, Löfdahl CG, Postma DS, et al. Effect of inhaled formoterol and budesonide on exacerbations of asthma. N Engl f Med 1997;337:1405-11.

11 Cheung D, Timmers MC, Zwinderman AH, et al. Long-term effects of a long-acting $\beta_{2}$-adrenoceptor agonist, salmeterol, on airway hyperresponsiveness in patients with mild asthma. N Engl f Med 1992;327:1198-203.

2 Bhagat R, Kalra S, Swystun VA, et al. Rapid onset of tolerance to the bronchoprotective effect of salmeterol. Chest 1995;108:1235-9.

13 Ramage L, Lipworth BJ, Ingram CG, et al. Reduced protection against exercise-induced bronchoconstriction after chronic dosing with salmeterol. Respir Med 1994;88:363-8.

14 Booth H, Bish R, Wallers J, et al. Salmeterol tachyphylaxis in steroid treated asthmatic subjects. Thorax 1996;51:1100-4.

15 Yates DH, Kharitonov SA, Barnes PJ. An inhaled glucocorticoid does not prevent tolerance to the bronchoprotective effect of a long-acting inhaled $\beta_{2}$-agonist. Am $\mathcal{F}$ Respir Crit Care Med 1996;154:1603-7. 
16 Kalra S, Swystun VA, Bhagat R, et al. Inhaled corticosteroids do not prevent the development of tolerance to the bronchoprotective effect of salmeterol. Chest 1996;109: 953-6.

17 Ullman A, Hedner J, Svedmyr N. Inhaled salmeterol and salbutamol in asthmatic patients: an evaluation of asthma symptoms and the possible development of tachyphylaxis. Am Rev Respir Dis 1990;142:571-5.

18 Yates DH, Sussman HS, Shaw MJ, et al. Regular formoterol treatment in mild asthma. Effect on bronchial responsive- ness during and after treatment. Am $\mathcal{F}$ Respir Crit Care Med

1995;152:1 170-4.
19 Newnham DM, Grove A, McDevitt DG, et al. Subsensitivity of bronchodilator and systemic $\beta_{2}$-adrenoceptor responses after regular twice daily treatment with eformoterol dry powder in asthmatic patients. Thorax 1995;50:497-504.

20 Verberne APH, Frost C, Roorda RJ, et al. One year treatment with salmeterol compared with beclomethasone in children with asthma. Am $\mathcal{f}$ Respir Crit Care Med 1997;156:688-95. 